\title{
RESEÑA: LA LEYENDA DE LAS DOS PIRATAS. MARÍA VILA ${ }^{1}$
}

\author{
Blanca Puchol Vázquez ${ }^{2}$
}

\section{María Vila. La Leyenda de las dos piratas. Barcelona: Planeta, 2017. ISBN: 9788408172475}

La editorial Planeta publicó el 13 de junio de 2017 La leyenda de las dos Piratas, obra de una escritora novel llamada María Vila. Si bien es verdad que no es el primer trabajo publicado por esta autora (en 2001 publicó, en la editorial Combra, una novela fantástica titulada Nadie, y en 2002 El tren fue publicado tras ganar el IX Premio del Certamen Nacional de Novela Corta J.L. Castillo-Puche), sí es su primera novela de ficción histórica además de, hasta ahora, su obra más extensa.

Mujeres, aventuras, romances, piratas, barcos, lealtades y traiciones... son algunas de las cosas ante las que el lector se encuentra una vez se sumerge en las páginas de esta apasionante novela:

Londres, año 1579. Dos jóvenes aristócratas -la futura condesa Inés Braukings y la princesa bastarda Victoria Dudley- se rebelan contra la vida que les corresponde por nacimiento y escapan en busca de libertad. Para huir lejos de la jaula de oro que el futuro les tiene reservada, se embarcarán en El Miguel, barco pirata que capitanea el hábil y frío Miguel Saavedra, amigo personal de la reina Isabel, la cual no sospecha de las actividades criminales del español. [...]

La leyenda de las dos piratas es una novela de aventuras, de duelos al atardecer, de amores imposibles, de intrigas y muertes, de amistades inquebrantables, en un tiempo en que solo el honor lograba dar sentido a la vida. (Vila 2017)

\footnotetext{
${ }^{1}$ Fecha de recepción: 23/04/2018.

Fecha de aceptación: 25/04/2018.

${ }^{2}$ Colaboradora Honorifica, Departamento de Estudios Ingleses: Lingüística y Literatura, Universidad Cumplutense de Madrid; y Profesora de Lengua Inglesa, Universidad Internacional de la Rioja; $\square$ blanca.puchol@unir.net.
} 
Así se presenta la novela en la sinopsis que aparece en la contraportada de su edición en papel. Y así es. A través de sus páginas su autora, María Vila, transporta al público a la Inglaterra de finales del XVI y hace que el lector viva, junto a las protagonistas, una serie de aventuras gracias a las cuales éstas van aprendiendo y madurando. Resulta necesario destacar aquí la monumental labor de documentación que se puede percibir según se avanza en la lectura de esta obra. Documentación que toca diversos temas tanto históricos como técnicos. De entre estos últimos cabe resaltar la documentación naval (cada barco, sus características, cada maniobra...), así como lo relacionado con el arte de la esgrima, algo que se deja ver en las descripciones de los diversos lances y batallas que acontecen a lo largo de la narración. En cuanto a la documentación histórica hay que comentar el papel destacado que tiene en esta novela la situación social en la que se encontraban las mujeres isabelinas.

Como reza la cita anterior, la novela comienza cuando Inés y Victoria, ante las exigencias de la vida que les corresponde por nacimiento, deciden rebelarse y escapar. Y lo hacen buscando una libertad de la que no gozan por el hecho de ser mujeres, por un lado, y, por otro lado, por pertenecer a los estamentos más altos de la sociedad del momento. Si bien es verdad que, precisamente por pertenecer a la nobleza, ambas gozan de la oportunidad de estudiar (saben leer y escribir, estudian lenguas como el latín, griego, francés o italiano, y ciertas habilidades como piano, baile...), por otro lado, su condición social las obliga a casarse con quienes sus progenitores elijan y vivir bajo la atenta mirada y autoridad de los varones de la familia (padre, hermano o esposo).

Sin embargo, hay que mencionar el hecho de que la acción de la historia que aquí nos ocupa tiene lugar en un tiempo regido, precisamente, por una mujer. Una mujer de la que muchos destacan "su independencia de carácter o sus intermitentes devaneos 
amorosos" (artehistoria) y que no contrajo matrimonio, entre otras cosas, para no perder su independencia y poder seguir reinando:

Understanding the subservient role of Elizabethan women provides an understanding as to why Queen Elizabeth was reluctant to marry. All of her immediate male relatives had died. She was answerable to no male member of the family.

Had she married all this would have changed. Elizabeth would have been expected to obey her husband. [...] the lives of Elizabethan women illustrate how, even Royal Woman were totally dominated by the male members of their families. (Elizabethan Era)

Por otro lado, en esa época las mujeres pertenecientes a las clases sociales más bajas, si bien también dependían de la autoridad de los varones de la familia, disfrutaban, no obstante, de una libertad de acción y decisión de la que, por el contrario, sus congéneres pertenecientes a la aristocracia no gozaban en absoluto. Cabe afirmar que estas últimas no solo estaban subyugadas a unas estrictas normas de conducta y decoro por el mero hecho de ser mujeres sino que a esto habría que sumar las normas y restricciones impuestas por el estatus social al que pertenecían.

Por tanto, cocineras, pescadoras, camareras... eran quienes, en mayor o menor medida, podían decidir qué querían hacer con su tiempo y cómo querían vivir su vida. Esto no significa que fueran completamente libres, pero sí que gozaban de una libertad con la que sus nobles congéneres, salvo rara excepción, no podían ni soñar. Ahora bien, si había alguien que podía decidir cómo vivir sin tener que dar explicaciones a nadie, estas eran las prostitutas.

Esta situación de la mujer del XVI encuentra perfecto reflejo en La leyenda de las dos piratas donde aparece, precisamente, como aquello contra lo que se rebelan sus 
protagonistas. Ejemplo de ello son las siguientes palabras que se pueden leer en sus páginas:

-Entonces, ¿qué es lo que quieres? -iQuiero ser libre! -exclamó la princesa-. Quiero poder elegir mi destino, elegir adónde ir, con quién, a quién amar... Escoger mis amistades, decidir por mí misma... -Lo que quieres es ser un hombre. Y eso no es posible, Victoria. Ninguna mujer tiene lo que tú quieres. (Vila, 2017: 59)

Pueden encontrarse varios ejemplos más de esto a lo largo de toda la novela, como el que tiene lugar cuando Glenne pregunta a Inés por qué luchan y esta responde:

- Luchamos por ser libres -dijo-. Por no tener que regresar a un hogar en el que un hombre elija nuestro destino -las otras dos mujeres la miraron-. Luchamos por poder vivir sin dar explicaciones, haciendo aquello que también sabemos hacer y que nos está vedado. Luchamos... -Inés miraba el mar, más allá de la costa- luchamos por no tener que esconder nuestros sentimientos, ni vivir presas... Por obrar y elegir y que sólo Dios nos juzgue. Y porque, cuando el día de mañana nos sentencien a morir en la horca, sea porque nosotras lo elegimos, y no por los actos de un padre, $\mathrm{o}$ de un esposo, que decidió por nosotras, como si fuéramos una extensión de su persona, una extensión insignificante y prescindible. (Vila 2017: 455)

Por ello, Inés y Victoria, una condesa y la otra princesa bastarda, deciden huir de sus hogares, lujos y comodidades, los cuales sacrifican sin pestañear, para buscar la ansiada libertad. Libertad para vivir como quieren, elegir a quién amar, adónde ir y qué hacer. Una vez se escapan, el público lector se ve arrastrado con ellas a una serie de viajes y aventuras a través de las cuales se puede observar la evolución y madurez que ambos personajes van adquiriendo a lo largo de las páginas.

Y no solo ellas. Esta es una novela coral en la que cada uno de los numerosos personajes que la conforman tiene un papel destacado en los diversos acontecimientos 
además de dejar una impronta fundamental no solo en el resto de personajes y su evolución sino también en el lector. Y este es, precisamente, uno de los rasgos más interesantes de esta novela: las diversas relaciones que se van estableciendo entre sus personajes, ya sea entre hombres, entre mujeres, hombres y mujeres, padres e hijos... relaciones de amor, odio o amistad... todas ellas distintas tanto en su naturaleza como en su intensidad.

El lector asiste, pues, a riñas entre padres e hijos; experimenta el odio de un hijo; el dolor de una madre; la incapacidad de amar de un padre; el ansia de un hijo por vengar y restablecer el buen nombre de su padre así como, por el contrario, la vergüenza de quien reprocha los actos de sus progenitores... Por otro lado, María Vila dibuja maravillosamente distintas historias de amor protagonizadas, algunas de ellas, por personajes que aman apasionadamente; otras por quienes aman por conveniencia; algunos de los personajes, por el contrario, no se atreven, o no se permiten admitir aquello que sienten; otros, sin embargo, no son afortunados o correspondidos...

Pero si de algo habla esta novela, si hay una relación humana que realmente importa aquí, esa es la AMISTAD. Sí, la amistad con mayúsculas. Y de nuevo, al igual que ocurre con las relaciones entre padres e hijos o las amorosas, su autora presenta una amplio y variado abanico de amistades. Así, uno se encuentra con la amistad o, mejor dicho, camaradería que une a los tripulantes de El Miguel, la amistad entre su capitán y el contramaestre, o la confianza y lealtad entre capitán y segundo de abordo. Por otro lado, es interesante ver cómo tanto Inés como Victoria logran ir haciéndose un huequito en esta tripulación a lo largo de su travesía con ellos, ganándose su respeto y cariño. 
Y, por supuesto, hay que destacar las relaciones que van surgiendo entre las mujeres que van conformando la tripulación de la Black Shadow. El lector presencia aquí cómo antiguas rencillas o enemistades pueden llegar a dejarse de lado por el bien común de toda una tripulación; cómo poco a poco unas y otras van conociéndose, apreciándose y respetándose, creando lazos de amistad y lealtad entre ellas; cómo todas y cada una de ellas aportan algo a la vida, crecimiento y evolución personal del resto...

Pero si hay una amistad que debe mencionarse aquí de manera especial, esa es la que une a Inés, Victoria y Shatidje. Entre ellas hay un amor incondicional; se conocen a la perfección y se aceptan; se quieren y respetan con todo, lo bueno y lo malo. El amor y la lealtad que se profesan son intensos e inquebrantables. Son ejemplo de una amistad por y para siempre y lo que ello conlleva.

Por todo ello no puedo más que estar de acuerdo con María Vila cuando, en una entrevista publicada en febrero de 2018 en el blog "Locas del romance", afirma que esta novela es un canto a la libertad. Pero no solo eso. Esta novela es, por encima de todas las cosas, un canto, sí, pero un canto a la amistad:

[...] Muchos me decís que Inés y Victoria comienzan La leyenda de las dos piratas siendo unas niñas y van madurando hasta volverse mujeres. Y es que la travesía de verdad, el viaje que ocurre en el libro es el viaje de su desarrollo, madurez y sobre todo de su amistad. La idea de fondo de esta historia es un canto a la amistad por encima de todo, a la amistad con la importancia e intensidad que tiene en nuestra adolescencia, pero vista desde la madurez. Y es un canto a la libertad [...] (Locas del romance)

Y este es el motivo por el cual no hay mejor manera de terminar esta reseña que con las palabras que cierran La leyenda de las dos piratas: "Victoria, Inés, Shatidje. La amistad no muere nunca" (Vila 2017: 949). 


\section{Referencias bibliográficas}

Artehistoria. https://www.artehistoria.com/es/contexto/la-inglaterra-isabelina [10 de abril de 2018].

Blog "Locas del romance": Entrevista realizada a la María Vila. http://locasdelromance.blogspot.com.es/2018/02/entrevista-maria-vila.html?m=1 https://www.artehistoria.com/es/contexto/la-inglaterra-isabelina $[10$ de abril de 2018].

Elizabethan Era. http://www.elizabethan-era.org.uk/elizabethan-women.htm [12 de abril de 2018].

Vila, María. 2017. La leyenda de las dos piratas. Barcelona: Planeta. 